\title{
DESIGN AND IMPLEMENTATION OF IOT BASED SMART POWER MONITORING AND MANAGEMENT SYSTEM USING WSNS
}

\author{
Iman Mohammed Nayyef and Assit.Prof. Anas Ali Husein \\ Department of Computer Engineering, Al-Nahrain University, Baghdad, Iraq
}

\begin{abstract}
We will design a system based on WSNs and IoT technologies to manage real-time power at buildings. This system comprises of: a wireless sensor network (sensing node and base station) and a smart home gateway. A sensing node is utilized wireless sensors to measure voltage and current; to calculate power consumption of connected appliances, transmitted wirelessly to a base station via Zigbee node. A base station is designed to receive all data transmitted from the sensing node and display it through GUI available at the personal computer, with the possibility of controlling ON and OFF appliances according to consumer requirements; All of these readings will be stored at database for analysis. In addition, a smart home gateway will connect the system with internet to allow consumers to continuous monitoring and remote control the appliances via a smartphone application. The benefit of this system, that the appliances control mechanism can be done in different ways (manually, automatically, and remotely). Various household appliances were tested to verify the accuracy of the electrical parameters that measured at system and compare them with practical measurement, found the average error ratio between them (0.3\%) was in voltage, (1.5\%) in current, and $(1.8 \%)$ in power.
\end{abstract}

\section{KEYWORDS}

IoT, WSN, Zigbee, Power Management, Smartphone app.

\section{INTRODUCTION}

Electrical energy is considered a main source of evolution and advance at the modern world. Technology evolves energy requirements, demand for energy is increasing day by day, and these energy demands occur in the domestic and industrial sectors. Demand for electricity is rising and the natural fuels are decreasing due to high energy use. The non-match between request and equipping, reduction of automation and control equipment, will be produced significant interruptions worldwide [1].

Therefore, inhabitancies and companies are beginning to research for best methods to assist decrease their rising electrical bills. One method of decrease these expenses through real-time monitoring, how much power is being consumed, and from this information make informed decisions about how to control the electrical devices being operated. A system that can give consumers an estimate of the amount of power consuming, will allow them to adjust their habits in order to reduce costs [2].

With the rapid development and expansion of Internet technology and the WSN, the home environment has seen a fast foreword of network permitted digital technology, which offers novel and exciting chances to expand the connection of appliances within the home for home automation. In recent years, WSNs is used for environmental monitoring, health monitoring and industrial monitoring as a means of reducing the energy consumption. WSNs are also highly flexible and supports power management using Web services and middleware technologies. WSN technology 
has demonstrated a great potential in management and collecting data such as humidity, pressure, temperature, electrical parameter, etc. This data that collected through the sensing node, will be transferred wirelessly to the control system for operation and management [3].

In this work, the system designed by the integration of WSNs with Web Service communications for power management using IoT platform, to monitor the power usage of AC devices in a home environment. Then, the consumed power will be displayed through a user-visible interface in real time; so consumers can readily realize the patterns of electricity consumption and adjust their behaviour to reduce power consuming and costs. The system permits for inexpensive monitoring of power usage and demonstrates a practical method to control power consumption through user interaction. Moreover, consumers can manually, automatically control the on/off appliances to effectively control power usage of appliances; and able to remotely control via smartphone application. The flexibility and configurability characteristics of our system are two key points for users, as well as low power consumption and system portability.

\section{RELATED WORK}

In 2011, Kim et.al. [4], they proposed a power management and control system based on wireless sensor networks. Where, wireless sensors were used to continually sense and updates electricity data and transmit it via zigbee module, in order to provide real-time electricity consumption information to users and remote monitoring and control of home appliances were provided to users through web service.

In 2013, Soliman et.al. [5], they explored the concept of Smart Home through integrating IoT with Web services and Cloud computing. Their approach consisted of embedding intelligence into sensors and actuators using Arduino platform, networking smart things using Zigbee technology and facilitating interactions with smart things using Cloud services for easy access in different locations. The approach was successfully used for demonstrating services for measuring home conditions, monitoring home appliances, and controlling home access. The infrastructure can be adopted for or adapted to other applications.

In 2014, Suryadevara et.al. [6], they proposed the pattern of a smart monitoring and controlling system for household electrical appliances in real time. This system monitors electrical parameters of household appliances were done by interfacing with fabricated sensing modules for transmitting wirelessly by zigbee protocol to central controller. In order to calculate the power consumed. this system implemented the controlling mechanism of appliances in different ways. the system was used for remote monitoring and control of appliances effectively through a website. Local and remote user interfaces were easy to handle by a consumer and are efficient in handling the operations.

In 2015, Sindhuja and Balamurugan [7], they designed the system to implement smart power monitoring and control through IoT using cloud data storage. Power consumed by various appliances is monitored through an ARM based controller interfaced to Hall Effect current sensors and stored in a cloud data base. Power control of home appliances is achieved through actuators such as relays which can be controlled by client with the help of a web server by establishing Remote Procedure Calls between client and server. The designed system was enabled client to monitor and control the appliances at home from anywhere availing the IoT features thereby reducing the wastage of energy.

In 2016, Kallur and Kulkarni [8], they created a smart power monitoring and control system toward the usage of an intelligent building. This framework adequately screens and controls the electrical machine utilizations at an elderly home. The electrical parameters of home machines were 
monitored by interfacing with sensor modules and the yield signals from it were incorporated and associated with ZigBee module for transmitting electrical parameters data wirelessly to the host PC which was stored the information into a database. The- system intended to decide the zones of day by day peak hours of power use levels and accompany an answer by which the system can bring down the utilization and improve better use of effectively restricted assets during peak hours.

In 2017, Joshi and khan, [9], they reported an effective implementation for Internet of Things used for monitoring home appliances, they presented wireless sensor networks based real time power management system to control and monitor the power consumption of electrical appliances in a home. For calculating the power consumption of electrical appliances was used current and voltage sensors. Then, these measured data was transmitted wirelessly using Zigbee protocol to the Ethernet shield for monitoring and controlling remotely through a secured internet web connection. Thus, this system can reduce electricity cost of the consumers

\section{Block Diagram Of Proposed System}

\subsection{SENSING NODE}

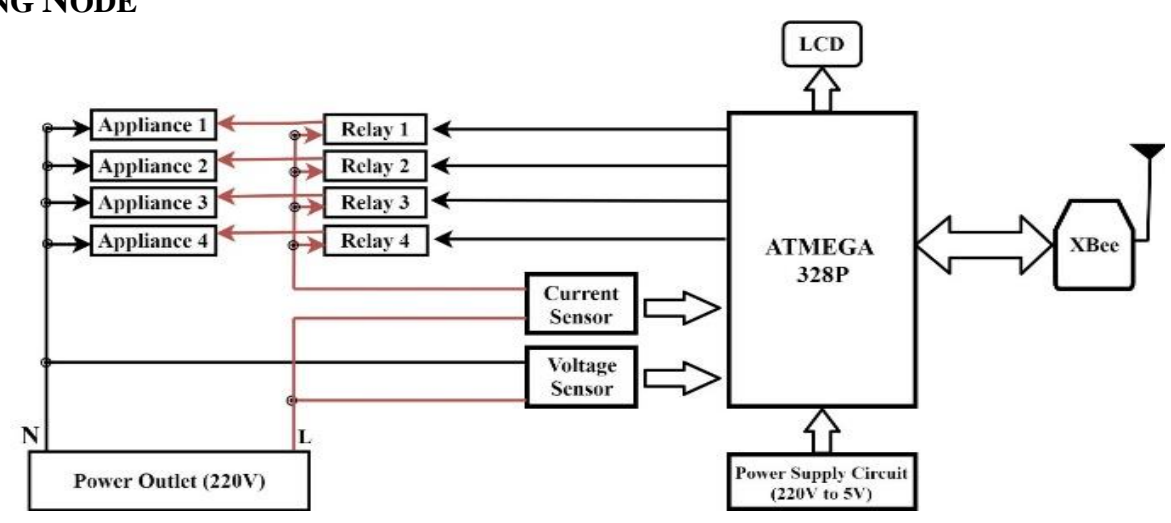

\subsection{BASE STATION}

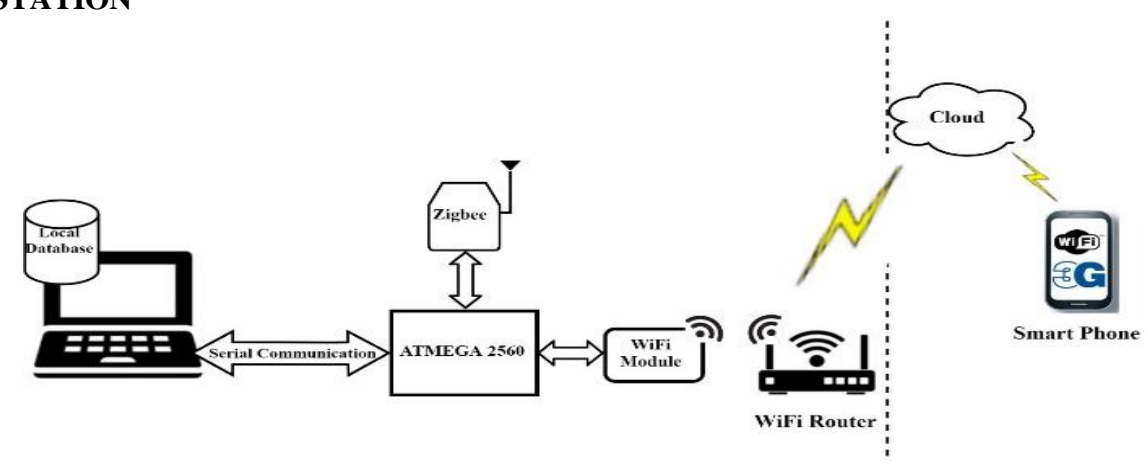

\section{SYSTEM OVERVIEW}

The proposed system is consisted of three parts: smartphone application, base station, and sensing node. Starting from the bottom, the sensing node uses a hall-effect based AC Current sensor and a transformer based AC voltage sensor with Arduino Uno microcontroller to calculate the real-time power consuming of connected electrical appliances. 


\subsection{Voltage Measurement}

The voltage sensor used in our work is single phase AC voltage sensor is made of ZMPT101B voltage transformer. Figure 1 shows a chip image of ZMPT101B. It is high precision, good consistency for measuring voltage and power and can reach $250 \mathrm{~V} \mathrm{AC}$. As well as low price, small size, and easy printed circuit board (PCB) mounting. The output signal from it, fed into the analog input channel of the microcontroller.

\subsection{CURRENT MEASUREMENT}

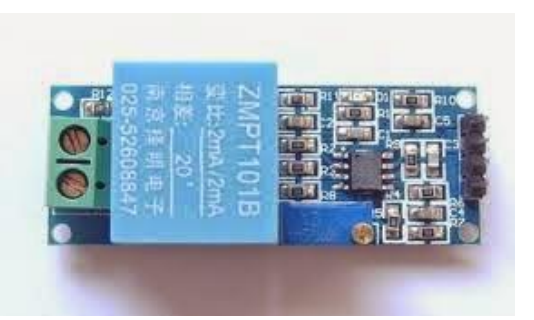

Figure 1. ZMPT101B chip.

For sensing current, we used ACS712 current sensor. Figure 2 shows the ACS712 chip. The main features of this sensor used to measure AC/DC current up to $20 \mathrm{~A}$. Its operating voltage is $5 \mathrm{~V}$. The output signal is fed to analog input channel of microcontroller. This sensor works on the basis of the hall effect principle, when a current pass through a conductor that is positioned at a magnetic field, a voltage is produced across its edges orthogonal to current and magnetic field directions.

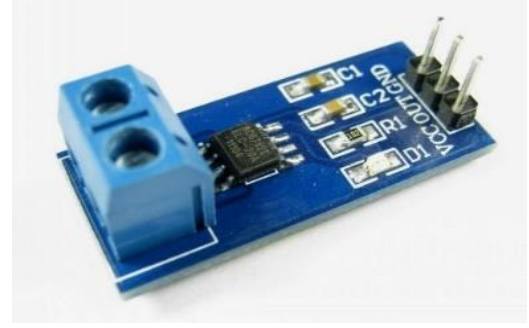

Figure 2. ACS712 chip.

\subsection{POWER MEASUREMENT}

For calculating power of a single-phase AC circuit, the output of volts and amperes must be multiplied by the power factor. Power Factor is the cosine of the phase angle of voltage and current waveforms as shown in the Figure 3. It is one, if voltage and current are in same phase. The current sensor output signal depends entirely on the nature of the connected appliance, whether the connected load is pure resistive, capacitive or is inductive [10]. 


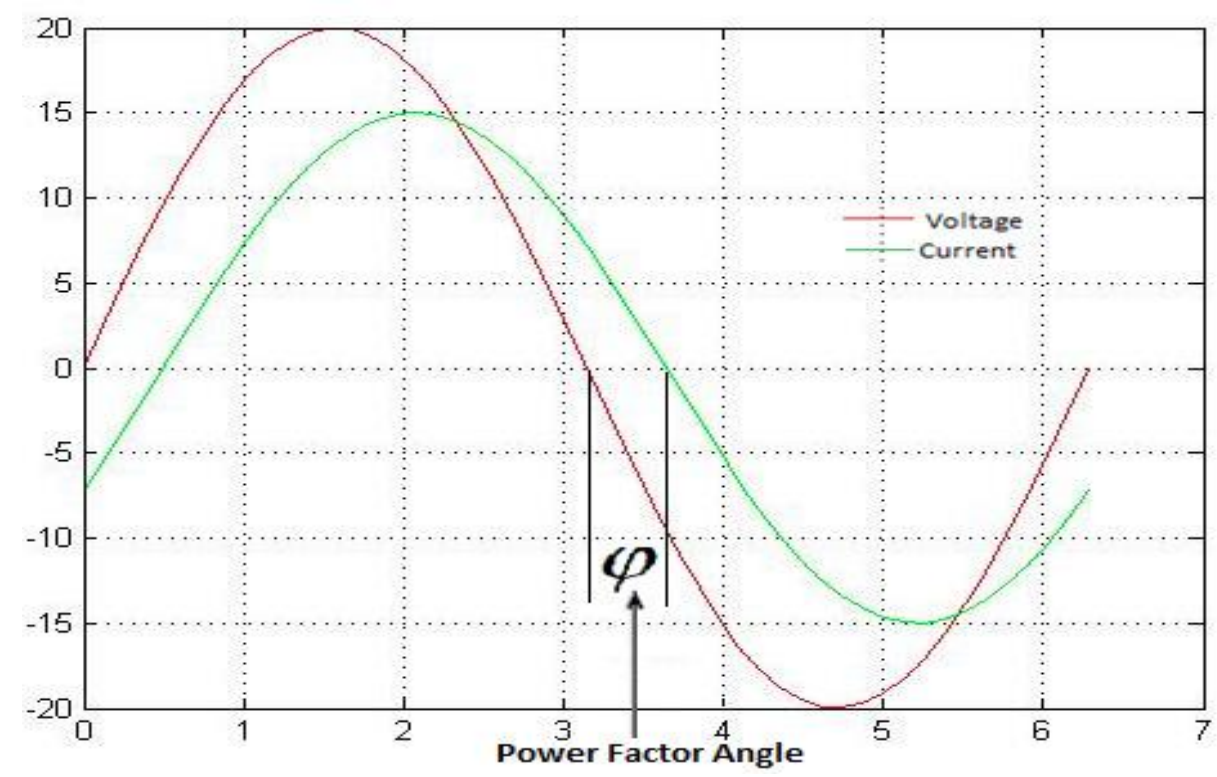

Figure 3. Representation of Power Factor.

The power is calculated at the microcontroller after receiving voltage outputs from corresponding current and voltage sensors as in (1).

$$
P=V r m s \times I r m s \times P . F
$$

Where

$\mathrm{P}=$ Calculated Power.

Vrms $=$ supplied voltage.

Irms $=$ drawn current.

$\mathrm{P} . \mathrm{F}=$ power factor.

Then, accumulated power consumption is calculated with run time of appliances, in order to calculated KWh as in (2).

$$
\operatorname{Energy}(K W h)=\frac{(\operatorname{Power}(W) \times \operatorname{Time}(t))}{1000}
$$

After completing the calculation, the measured readings will display using the liquid crystal display (LCD). In addition, relay is added to allow control of appliances either according to consumer requirements by sending commands wirelessly from a base station to a microcontroller or when exceeding permitted consumption limits, it will automatically turn off the power. ZigBee module will be responsible for sending wirelessly all the measured readings in this part to the base station. The base station is designed to receive all transmitted measured readings from sensing node to continue monitoring in real-time through GUI available at computer system and the mobile app window. Power monitoring feature allows the user to reduce the power consumption thus save cost. these measured readings are stored in database for further analysis. Then, this measured readings will be send via internet to the upper most application layer which has different applications on different level for different purposes. For information accumulation and information preparing at base station it utilized microcontroller - NodeMCU is Wi-Fi ensured single chip microcontroller unit (MCU) shown [Figure 4 (a)]. known as a Wi-Fi Module, it has ability to perform Wi-Fi related activities like IoT applications and home automation. It is used as an alternative to Arduino Wi-Fi shield in order to connect to a Wi-Fi network, because it is considered an inexpensive alternative, 
with default firmware and it has the same functions as Wi-Fi Shield. It is also immediately breadboard friendly. It incorporates inserted TCP/IP stack and numerous Internet conventions for simple web get to.

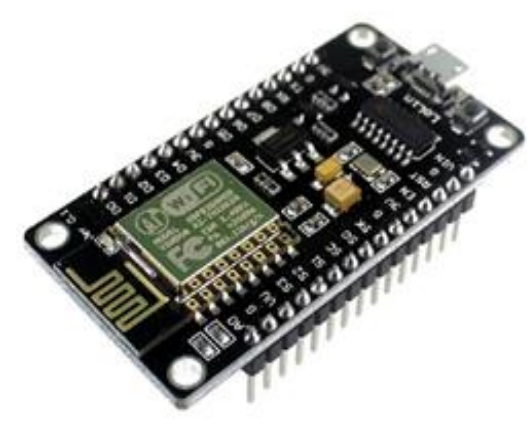

Figure 4 (a). NodeMCU Chip.

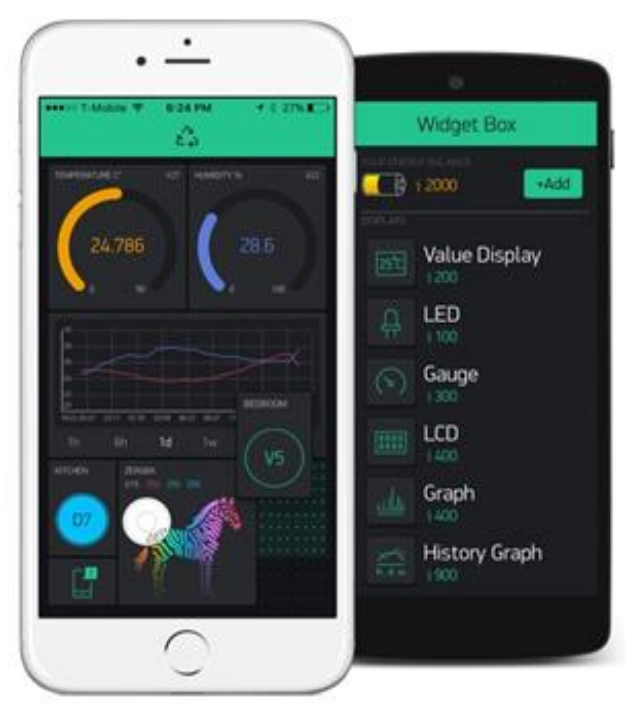

Figure 4 (b). Blynk App.

There are three major parts to a smartphone application. They are the device, cloud server and the mobile app. all of these features and techniques utilized in this project are outlined below. Blynk is a smartphone application that allows the developers to create a custom app for their projects' according to the application shown Figure 4 (b). It leverages the resources of a smartphone such as the touch screen to provide a set of widgets that assists to create a custom user interface to control the device remotely. It consists of two main elements, an application running on Android and iOS and a library compatible with the Wiring framework with our project board. Blynk app that is shown in Figure 4 (c) handles the data translation between the device and the smartphone app.

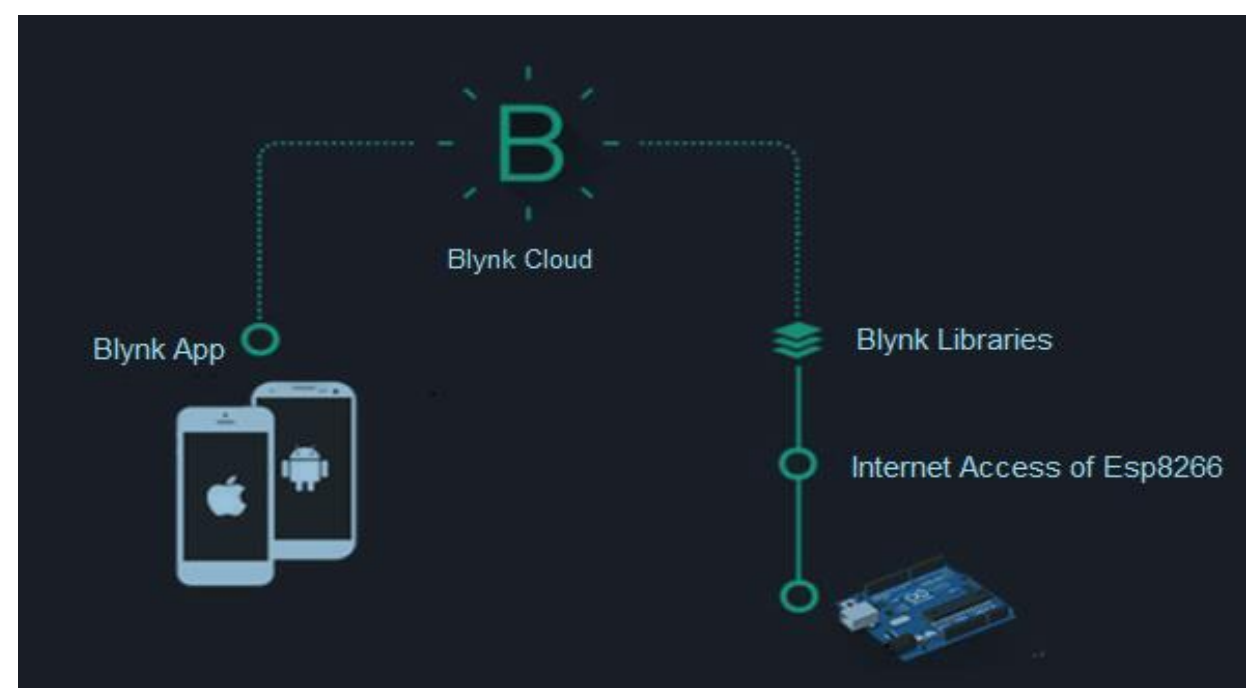

Figure 4 (c). Blynk-Cloud Platform. 
When the project application is registered; the server issues authentication token which must be included in the main project code. It also enables the device to communicate between each other and also between other web applications over internet. Before associating the gadget to a get to access point, it needs to join the system safely. Wi-Fi provisioning is the process of connecting a new Wi-Fi device (station) to a Wi-Fi network. The provisioning process involves loading the station with the network name referred as SSID and its security credentials. The user needs to send the predefined password. User can download the android mobile app from Google Play or iOS mobile app from App Store.

Figure 5(a) and Figure 5(b) illustrate wiring diagram of base station and sensing node, Figure 6 depicts the fabricated system with the integrated sensing circuit and ZigBee module.

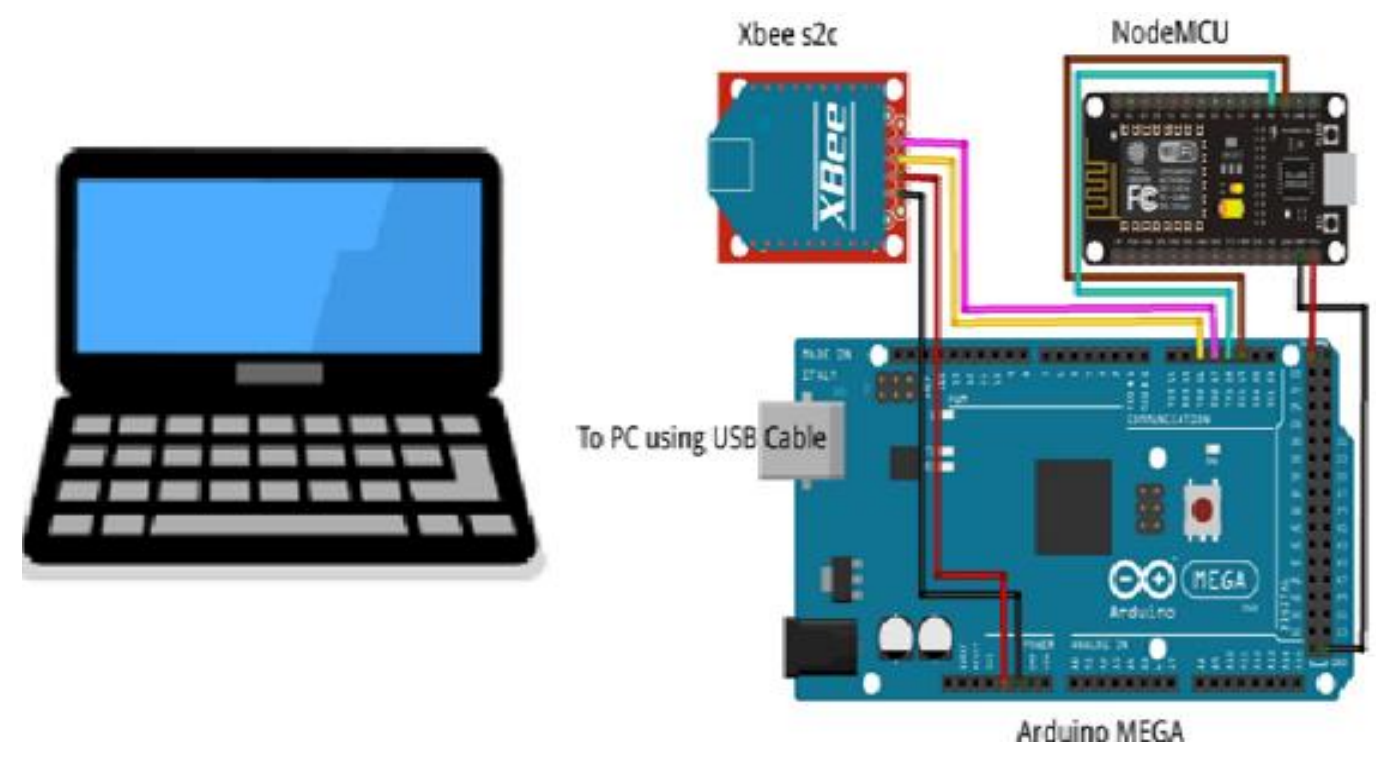

Figure 5 (a). Wiring diagram of the base station.

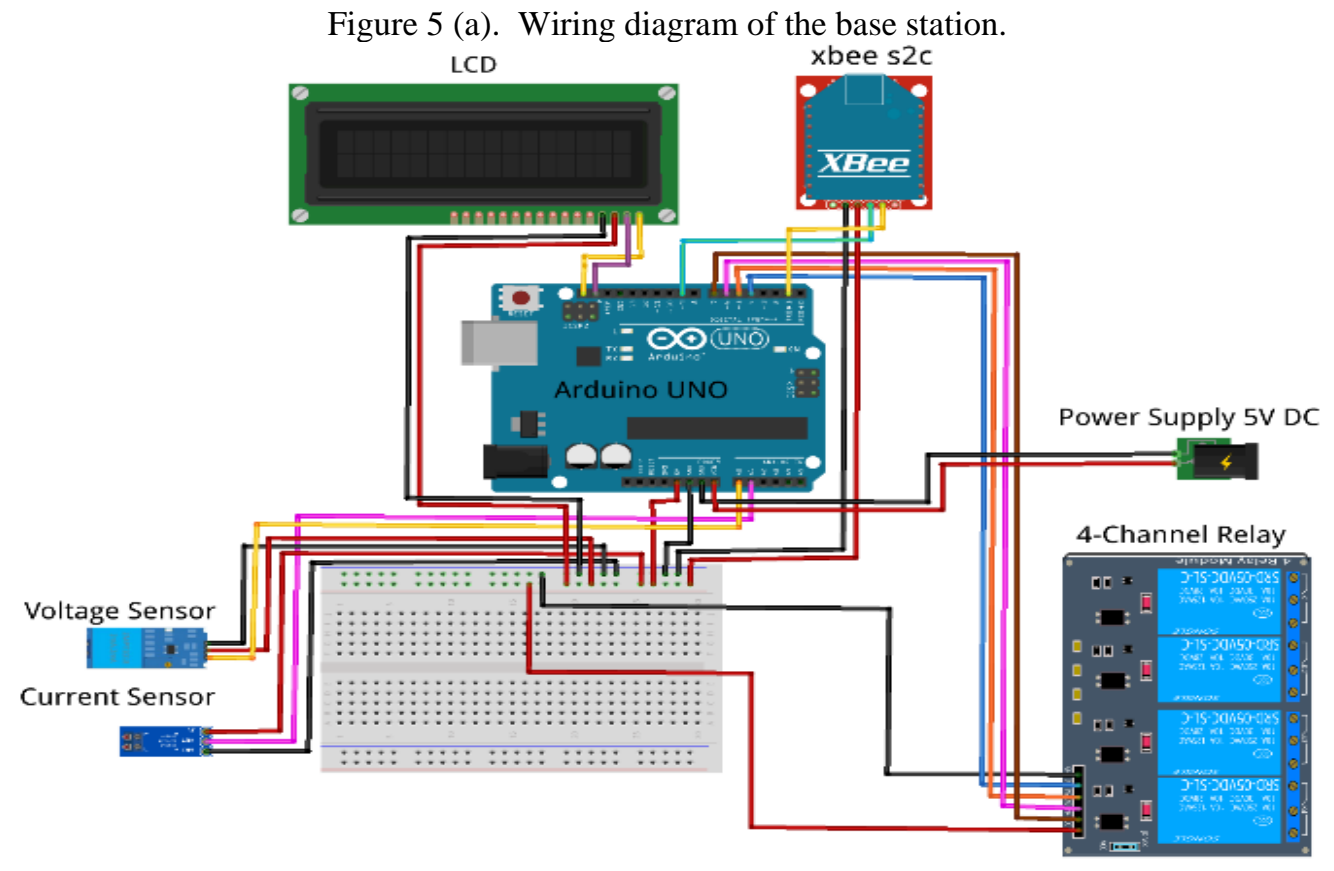

Figure 5 (b). Wiring diagram of the sensing node. 


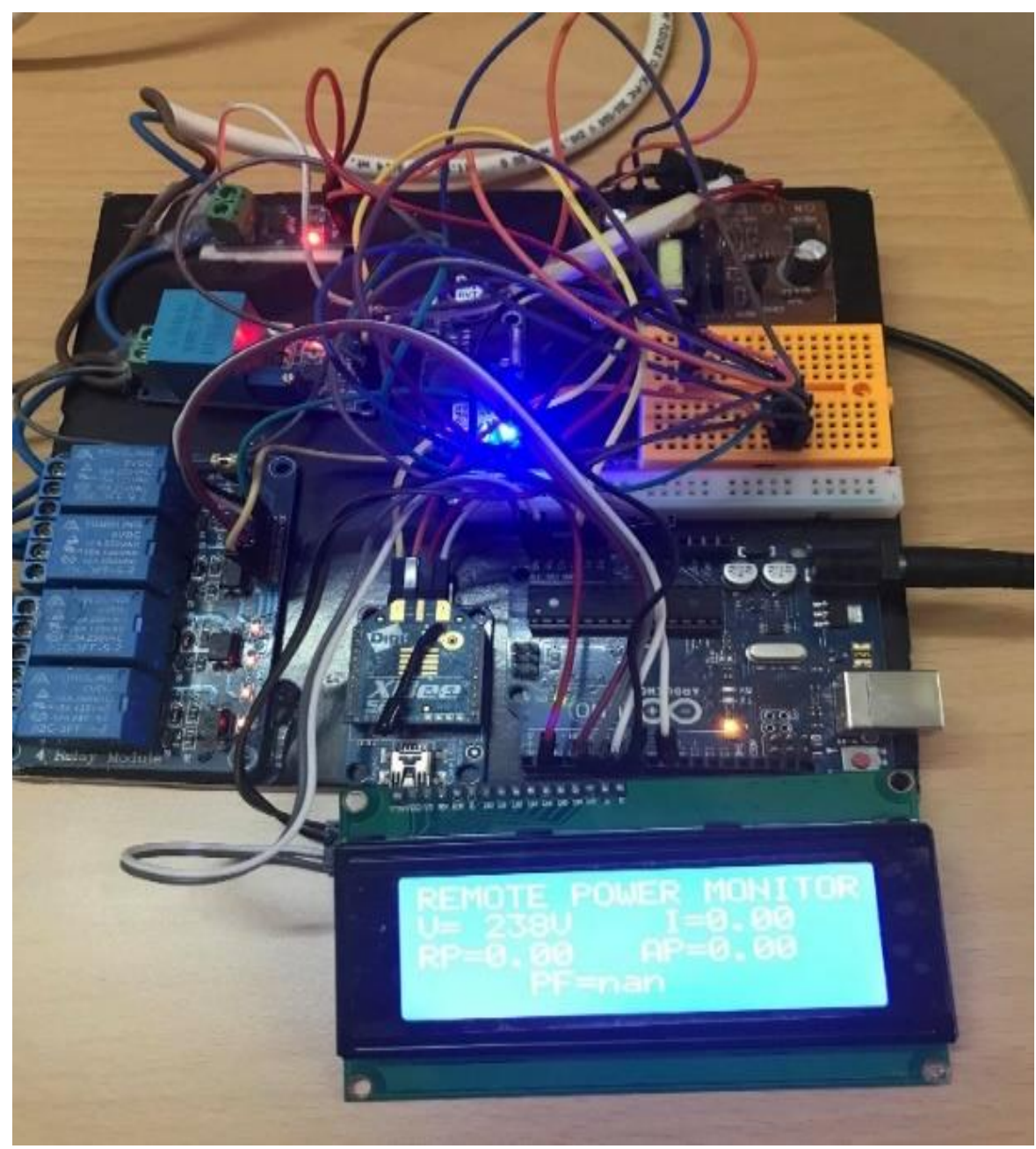

Figure 6. Fabricated smart power monitoring unit.

\section{SYSTEM IMPLEMENTATION AND RESULTS}

By monitoring the power consumption of the devices, the data is collected by the ZigBee coordinator for the base station, and saves all these data in the database at computer system for processing and analysed, as well as save in cloud database for remote access. Parameters that will store, the voltage, current, power factor, real and apparent power, and status of each relay, KWh and cumulative runtime of the system. The data for these parameters will be displayed through GUI and smartphone app window. Suitable actions, as turning devices ON or OFF, are done from the GUI or smartphone app screen according to consumer requirements. Figure 7 [(a) - (b)] displays the electrical parameters on GUI and Blynk app; as example, when light bulb, television and laptop charger have been connected to the sensing node. In addition, the system depends on the average of drawn current that is identified in the program (13A), which means the appliances can be turned on or off automatically, the relays work and the power is cut when the drawn current exceeds $13 \mathrm{~A}$, as shown in Figure 7(c). The measured readings are processed using visual studio programming. 
International Journal of Embedded Systems and Applications (IJESA), Vol 8, No.4, December 2018

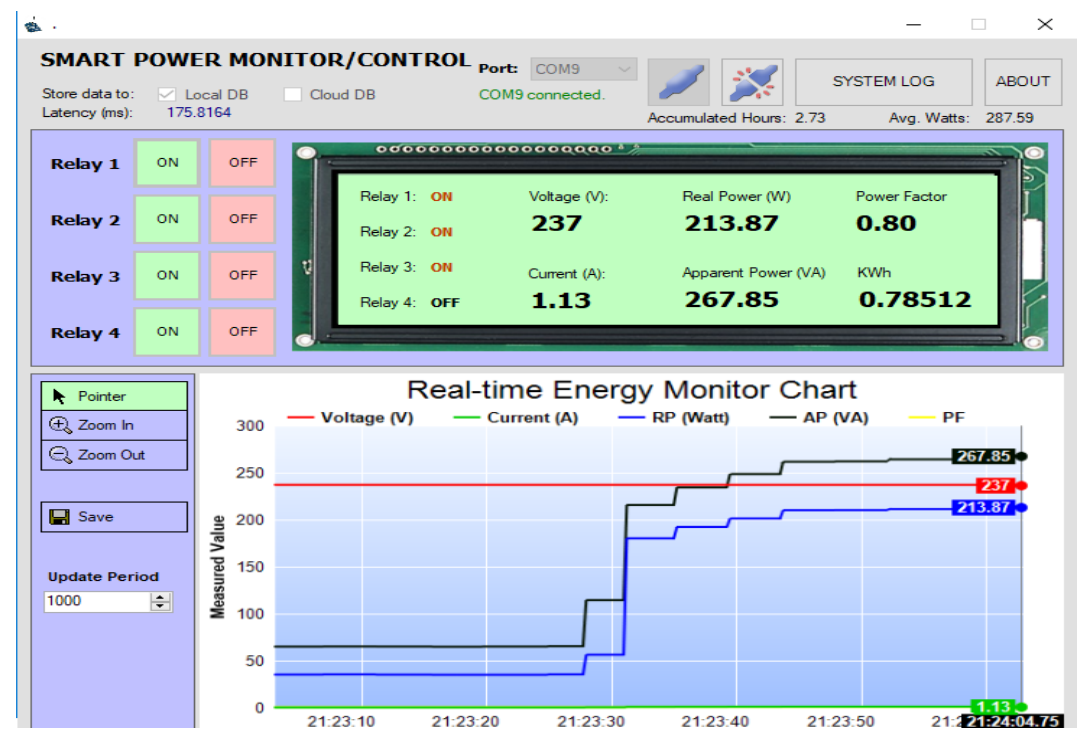

Figure 7 (a). Screenshot of GUI.

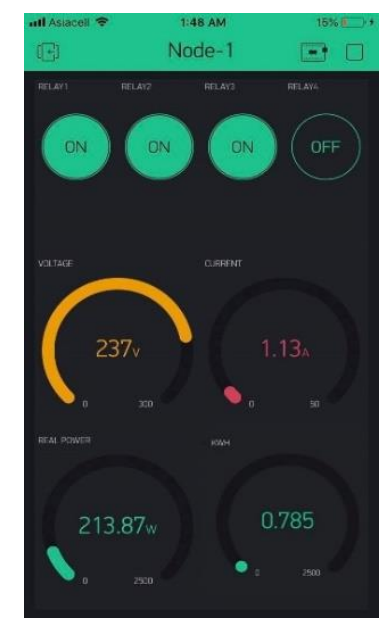

Figure 7 (b). Screenshot of Blynk

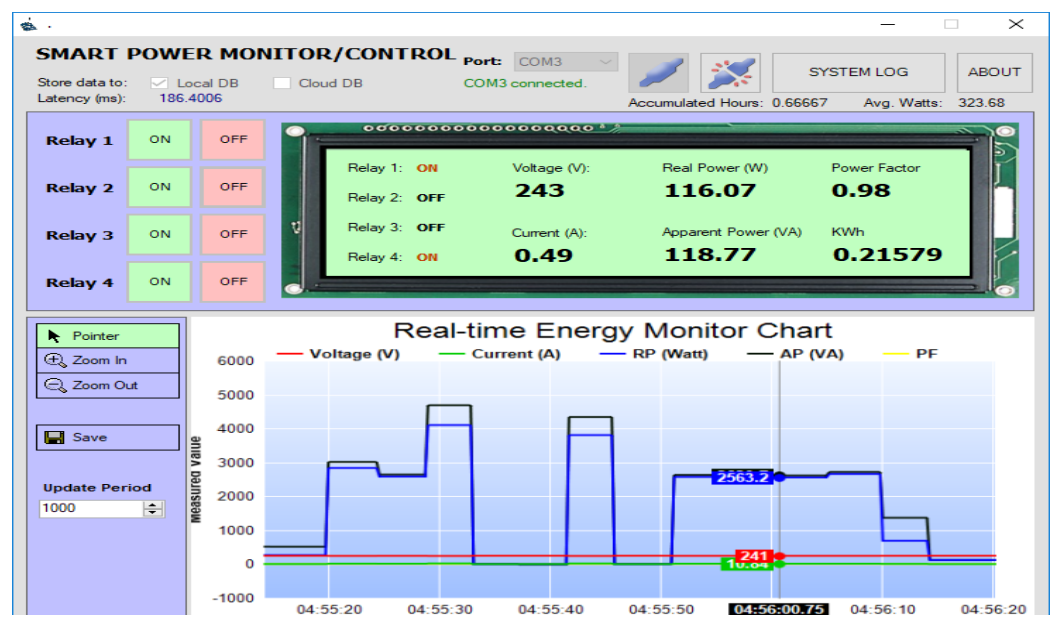

Figure 7 (c). Automatically turn off power of appliances at (13 A). 
International Journal of Embedded Systems and Applications (IJESA), Vol 8, No.4, December 2018

This section presents the results obtained from tested various household electrical appliances. Figure 8 displays the electrical appliances connected with installed sensing node. Sensing node hardware has been prepared, so user can be turning on four appliances simultaneously at sensing node to be a fairly economical design.
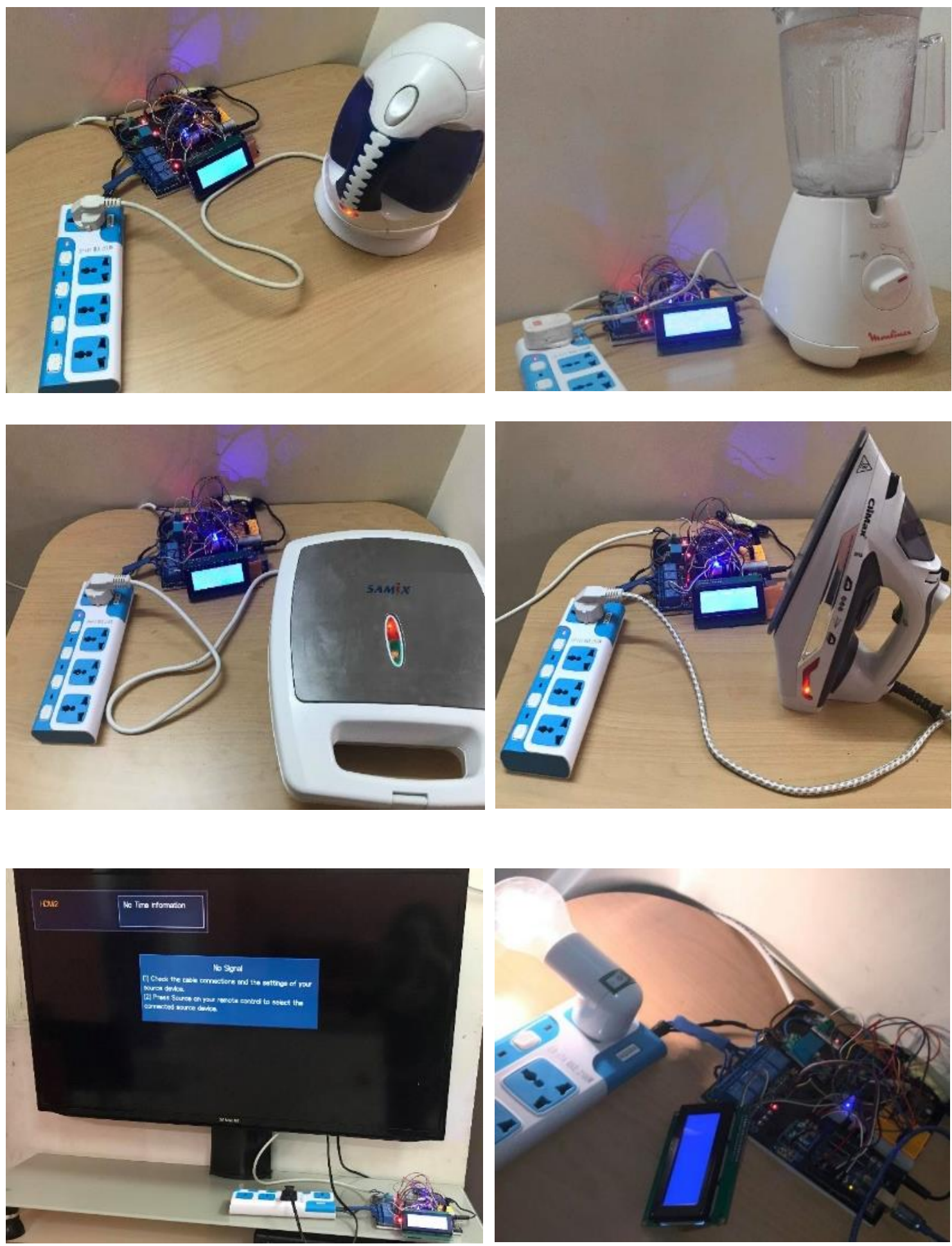

Figure 8. Various household electrical appliances connected to sensing node. 
International Journal of Embedded Systems and Applications (IJESA), Vol 8, No.4, December 2018

Table 1: Test of the system to measure the electrical parameters of some household appliances

\begin{tabular}{|c|c|c|c|c|c|c|c|c|c|}
\hline \multirow[b]{2}{*}{ Appliances } & \multicolumn{2}{|c|}{ Voltage (V) } & \multicolumn{2}{|c|}{ Current (A) } & \multirow[b]{2}{*}{ PF } & \multicolumn{2}{|c|}{ Real Power (W) } & \multicolumn{2}{|c|}{ APP (VA) } \\
\hline & $\begin{array}{c}\text { V- } \\
\text { meter }\end{array}$ & $\begin{array}{c}\text { Syste } \\
\text { m }\end{array}$ & $\begin{array}{c}\text { A- } \\
\text { mete } \\
\text { r }\end{array}$ & $\begin{array}{c}\text { Syste } \\
\text { m }\end{array}$ & & $\begin{array}{c}\text { Practic } \\
\text { al }\end{array}$ & $\begin{array}{c}\text { Syste } \\
\text { m }\end{array}$ & $\begin{array}{c}\text { Practic } \\
\text { al }\end{array}$ & $\begin{array}{c}\text { Syste } \\
\text { m }\end{array}$ \\
\hline Bulb light & 235 & 234 & 0.5 & 0.48 & $\begin{array}{c}0.9 \\
8\end{array}$ & 115.2 & 110.1 & 117.5 & 112.3 \\
\hline Iron & 235 & 234 & 10.6 & 10.57 & $\begin{array}{c}0.9 \\
8\end{array}$ & 2441.2 & 2424 & 2491 & 2473 \\
\hline $\begin{array}{l}\text { Water } \\
\text { heater }\end{array}$ & 236 & 235 & 9.25 & 9.22 & $\begin{array}{c}0.9 \\
8\end{array}$ & 2139.3 & 2123 & 2183 & 2167 \\
\hline Toaster & 221 & 220 & 6.55 & 6.54 & $\begin{array}{c}0.9 \\
8\end{array}$ & 1418.6 & 1410 & 1448 & 1439 \\
\hline TV & 224 & 223 & 0.32 & 0.31 & $\begin{array}{c}0.4 \\
7\end{array}$ & 33.7 & 32.5 & 71.68 & 69.13 \\
\hline Mixer1 & 222 & 222 & 0.5 & 0.5 & $\begin{array}{c}0.8 \\
4\end{array}$ & 93.2 & 93.2 & 111 & 111 \\
\hline Mixer2 & 222 & 221 & 0.66 & 0.65 & $\begin{array}{c}0.9 \\
3\end{array}$ & 136.3 & 133.6 & 146.5 & 143.7 \\
\hline $\begin{array}{l}\text { Laptop } \\
\text { charger }\end{array}$ & 236 & 236 & 0.26 & 0.25 & $\begin{array}{c}0.4 \\
4\end{array}$ & 27 & 26 & 61.36 & 59 \\
\hline $\begin{array}{c}\text { Refrigerato } \\
\text { r }\end{array}$ & 236 & 236 & 1.62 & 1.61 & $\begin{array}{c}0.3 \\
2\end{array}$ & 122.3 & 121.6 & 382.3 & 380 \\
\hline
\end{tabular}

Table 1 presents the measurement of the electrical parameters of household appliances and compared with practical results using the same appliances.

The electrical parameters are obtained from the system versus practical results graph as shown in Figure. 9 (a, b, c, d).

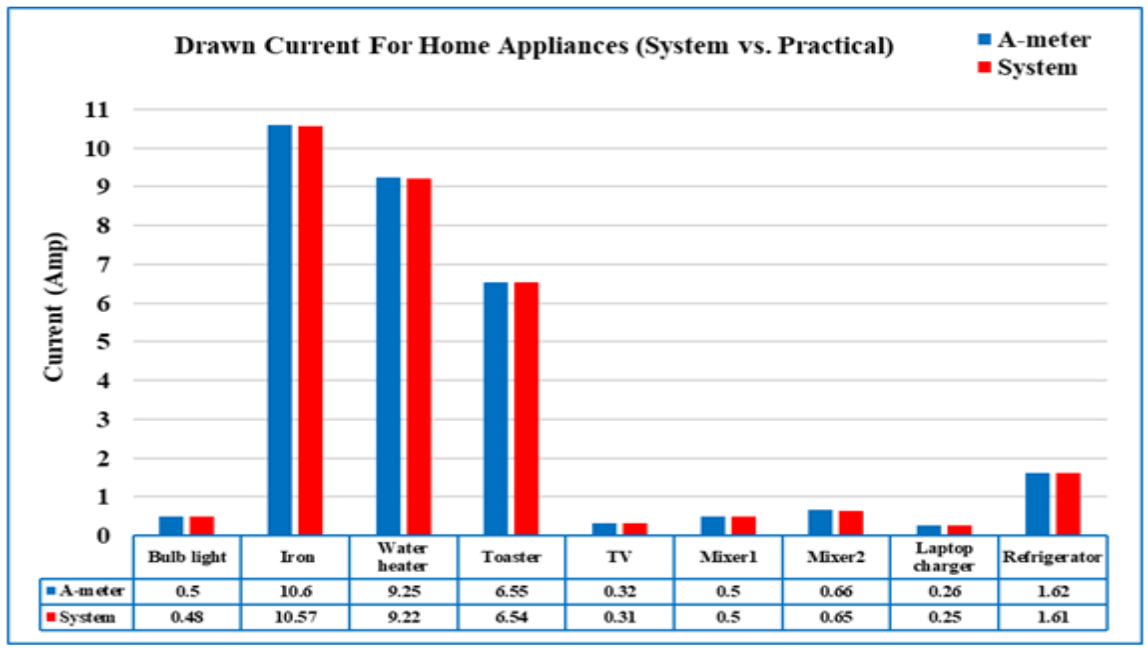

Figure 9 (a). Comparison between drawn current of system and practical. 
International Journal of Embedded Systems and Applications (IJESA), Vol 8, No.4, December 2018

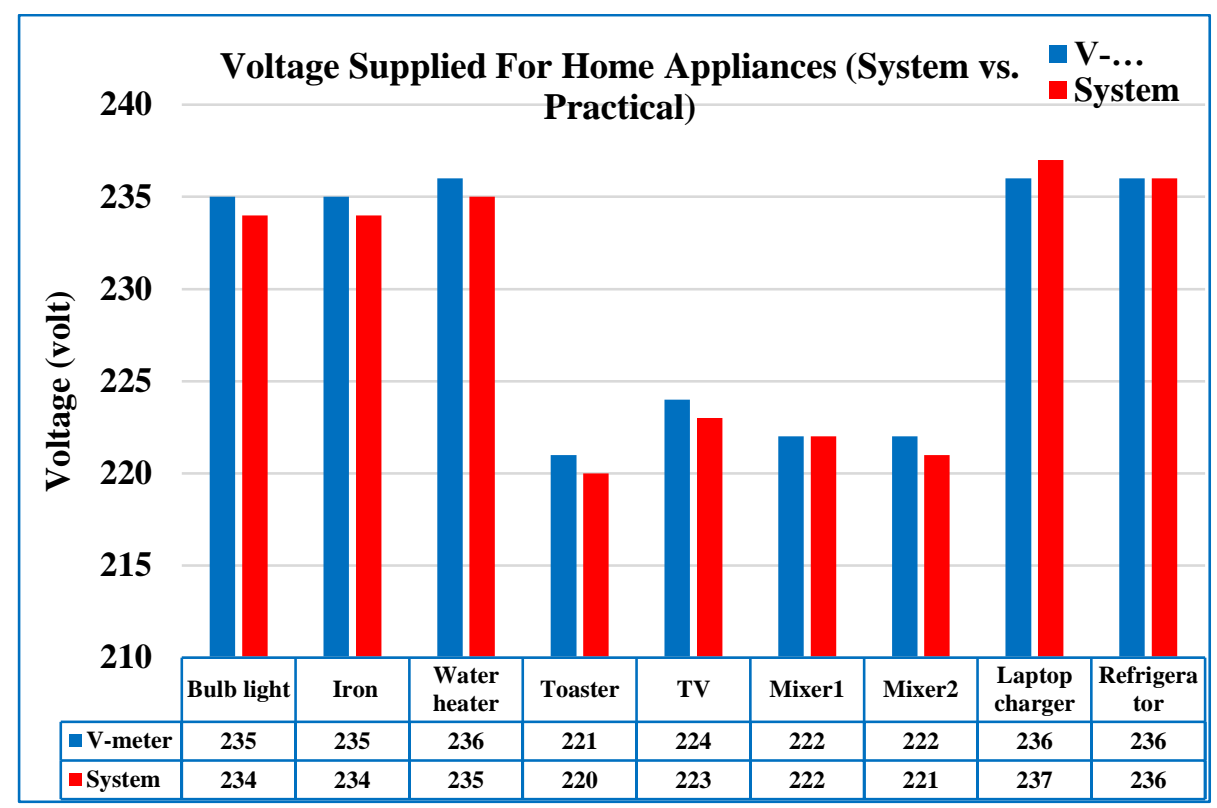

Figure 9 (b). Comparison between supplied voltage of system and practical

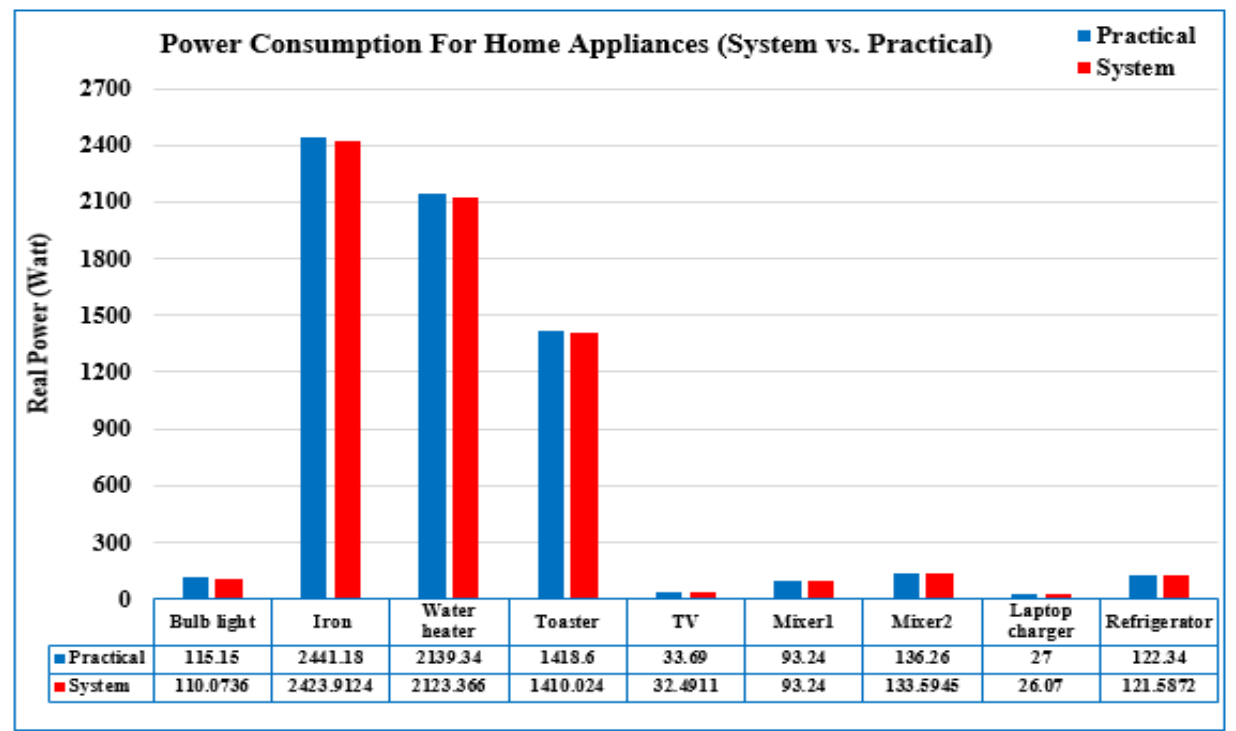

Figure 9 (c). Comparison between power consumption of system and practical. 


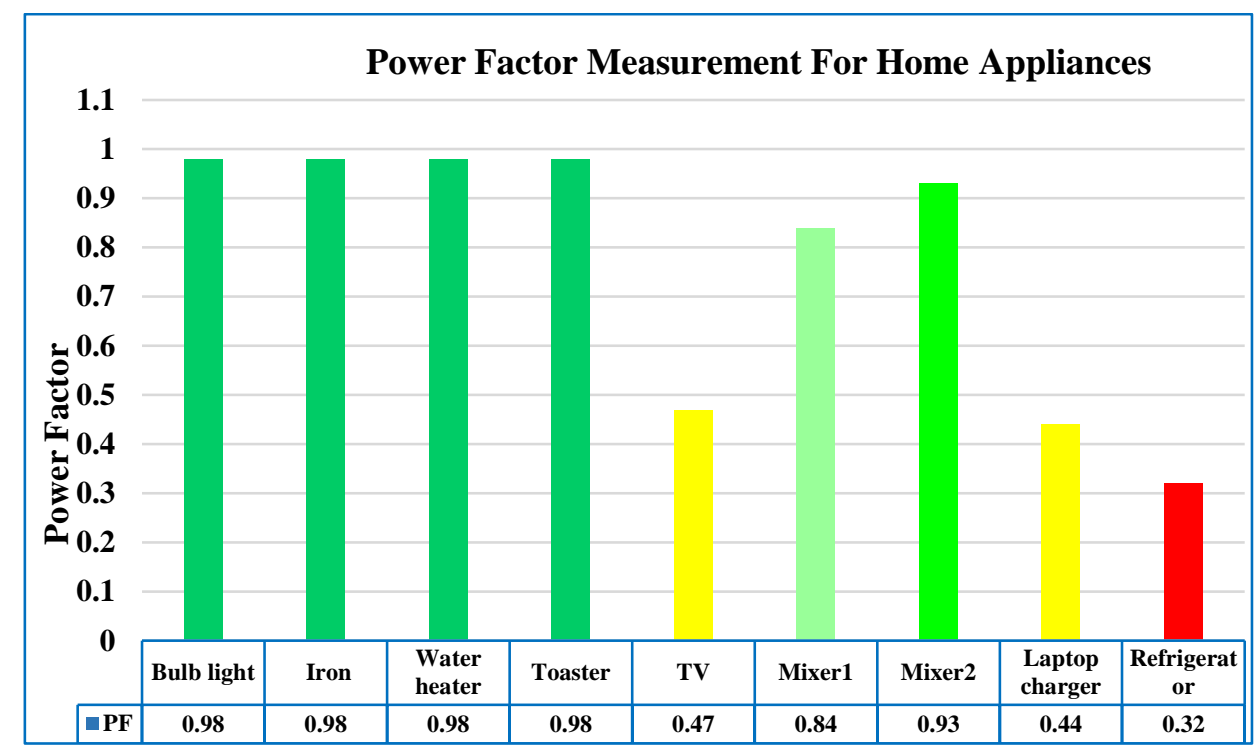

Figure 9 (d). Power factor measurement for different home appliances.

The power factor is a very important parameter on which the real power value depends. The power factor values vary from appliance to another from 0 to 1 depending on the type of load.

As shown in Figure 9 (d), the power factor value varies for each appliance, when the appliance is such as a lamp, an iron, a water heater and a toaster, this means resistive type; its value is close to 1. Either the remaining appliances are of an inductive type; its value is far from 1. Note, through Figure 10 (a) that shows real power versus apparent power graph, when PF value is 0.98 . This means that the type of load is almost resistant (current and voltage in-phase). In this case, the lost power will be very small, so the value of real power is approaching the apparent power. Figure 10 (b) shows real power versus apparent power graph when PF value is 0.5 . This means that the load type is inductive.

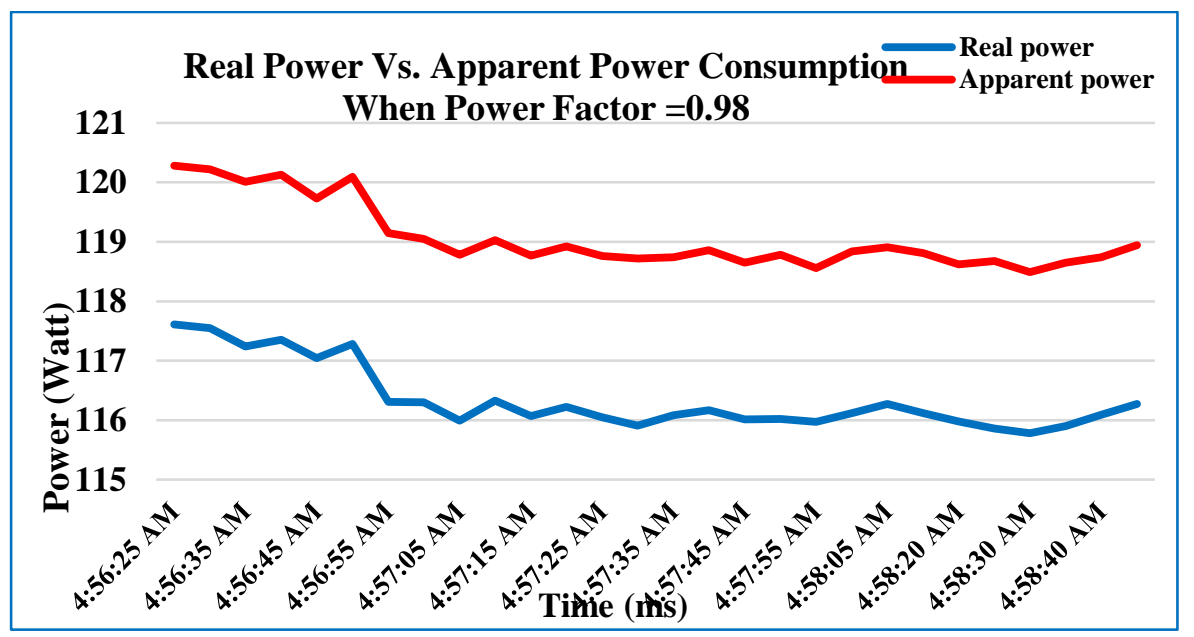

Figure 10 (a). Real power vs apparent power consumption $(\mathrm{PF}=0.98)$. 
International Journal of Embedded Systems and Applications (IJESA), Vol 8, No.4, December 2018

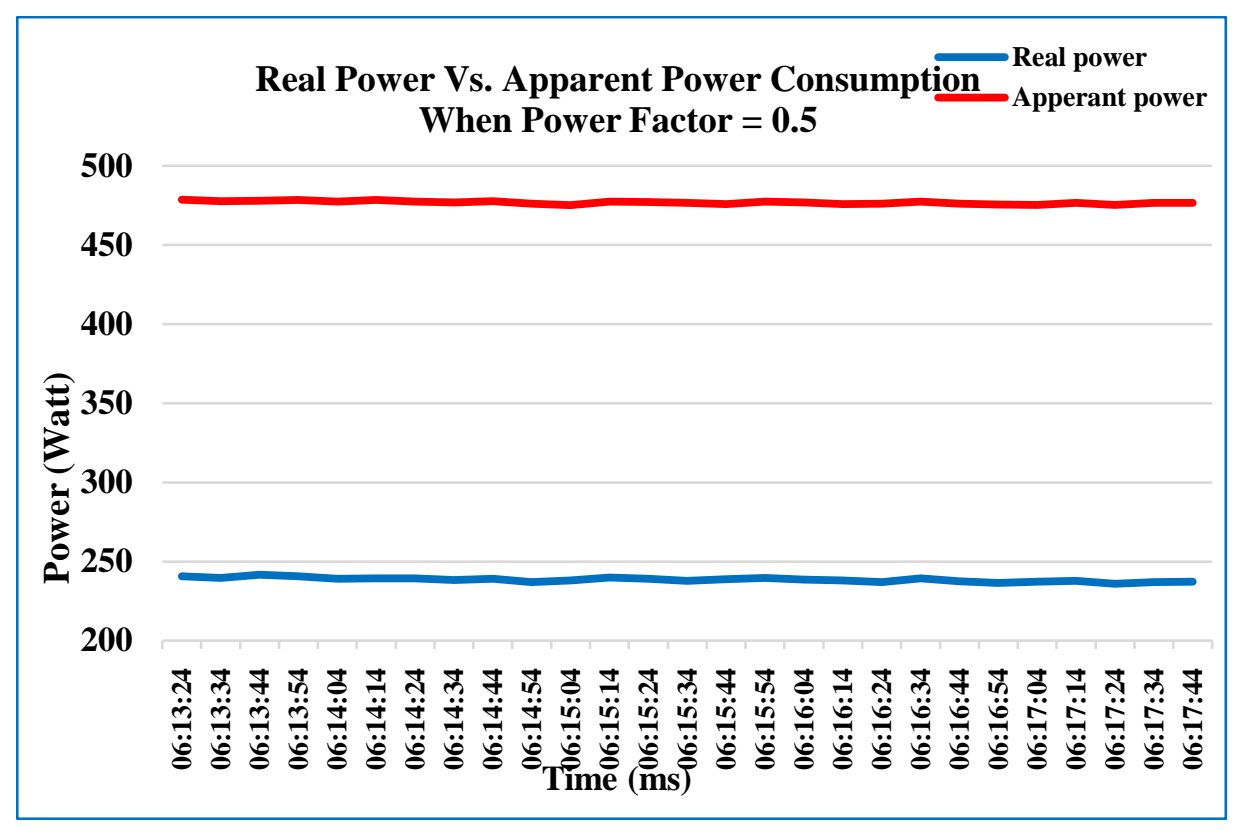

Figure 10 (b). Real power vs apparent power consumption $(\mathrm{PF}=0.5)$.

In addition, the sensing node is tested to check the $\mathrm{kWh}$ consumption at different run-times of the system. Figure 11 (a) shows KWh consumption when runtime of system (15 minutes) and Figure 11 (b) when runtime of system ( 2 hours). A direct conclusion can be obtained from these figures that $\mathrm{kWh}$ increased with operating time of the system depending on the average of cumulative power consumption.

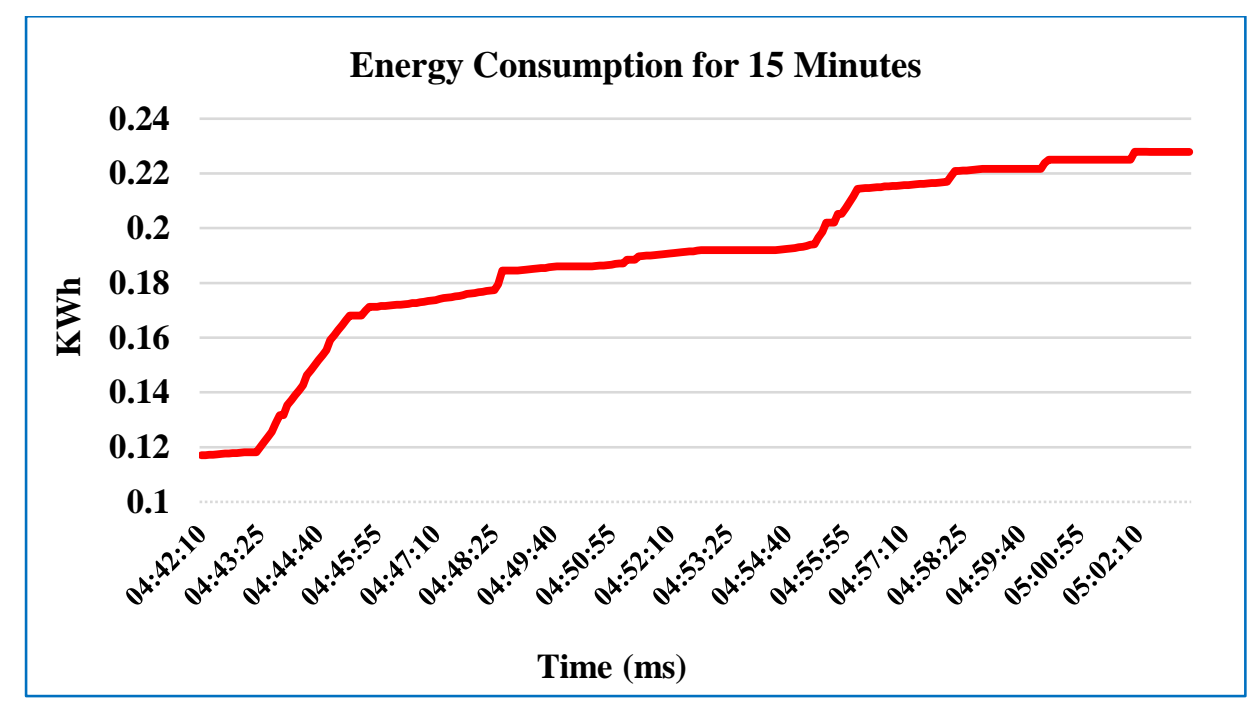

Figure 11 (a). Energy consumption (KWh) for 15 Minutes. 


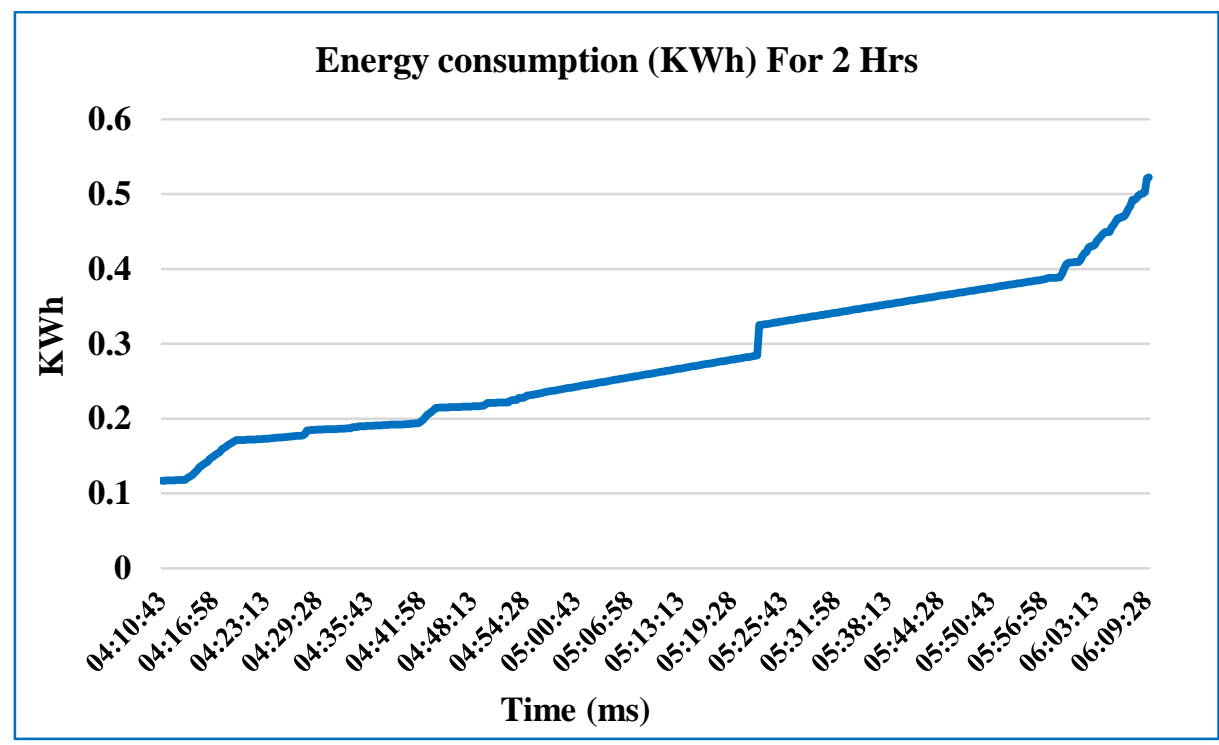

Figure 11 (b). Energy consumption (KWh) for 2 hours.

\section{Conclusion And Future Work}

Awareness of electricity consumption in the home or building is a first step towards saving power. The combination of WSN and IoT technologies for monitoring and controlling power consumption in real time is a powerful way for reducing power usage. With effective management about power consumption and control of household appliances, users can be motivated and encouraged to change their behaviours on energy use such as turning off lights or reducing heat. These small changes in behaviours can lead to significant energy savings. This paper presents a smart power management system for homes and buildings. The proposed system can monitor and measure electricity usage in real-time. With the proposed system, users can automatically, manually, and remotely control real-time electricity usage, Thus, the real-time monitoring of the electrical appliances can be viewed through GUI and smartphone app. This system is easy to design and consume less power, and provides at low cost. Various household appliances were tested to verify the accuracy of the electrical parameters that measured at system and compare them with practical measurement, found the average error ratio between them $(0.3 \%)$ was in voltage, $(1.5 \%)$ in current, and $(1.8 \%)$ in power. The energy consumption $(\mathrm{kWh})$ is increased with operating time of the system depending on the average of cumulative power consumption, when system is operated 15 minutes, $\mathrm{KWh}$ is 0.2284 ; system is operated 2 hours, KWh is $0.52241 \mathrm{In}$ future the system can be extended for monitoring the whole institute, schools, colleges, companies etc.

\section{REFERENCES}

[1] P. R. Joshi \& M. S. khan, (2017) "IOT Based Smart Power Management System Using WSN", International Research Journal of Engineering and Technology (IRJET), Vol. 04, No. 06, pp783-786.

[2] E. Chobot, D. Newby, R. Chandler, N. Abu-Mulaweh, C. Chen \& C. Pomalaza-Ráez, (2013) "DESIGN AND IMPLEMENTATION OF A WIRELESS SENSOR AND ACTUATOR NETWORK FOR ENERGY MEASUREMENT AND CONTROL AT HOME", International Journal of Embedded Systems and Applications (IJESA), Vol.3, No.1, pp1-15.

[3] S. G. Phuke \& K. N. Kasat. (2015) “A Review of Smart Power Monitoring and Controlling System in View of an Intelligent Building”, International Journal of Innovative and Emerging Research in Engineering, Vol. 2, No. 2, pp169-173. 
[4] W. H. Kim, S. Lee \& J. Hwang, (2011) "Real-time Energy Monitoring and Controlling System based on ZigBee Sensor Networks”, Elsevier Procedia Computer Science(PCS), pp. 794-797.

[5] M. Soliman, T. Abiodun, T. Hamouda, J. Zhou \& C.H. Lung, (2013) "Smart Home: Integrated Internet of Things with Web Services and Cloud Computing", in Proc. IEEE 5th international Conf. Cloud Computing Technology and Science, Bristol, UK, pp. 317 - 320.

[6] N. K. Suryadevara, S. C. Mukhopadhyay, S. T. Kelly, and S. P. S. Gill, (2015) "WSN-Based Smart Sensors and Actuator for Power Management in Intelligent Buildings", IEEE/ASME Transactions on Mechatronics, Vol. 20, No. 2, pp564 - 571.

[7] P. Sindhuja \& M. S. Balamurugan, (2014) "Smart Power Monitoring and Control System through Internet of things using Cloud Data Storage", INDIAN JOURNAL OF SCIENCE AND TECHNOLOGY, Vol. 8, No.19, pp1-7.

[8] V. S. Kallur \& S. N. Kulkarni, (2016) "Power Management, Monitoring and Controlling in Intelligent Buildings Using Wireless Sensor Network (WSN)”, International Research Journal of Engineering and Technology (IRJET), Vol. 03, No. 07, pp1350-1355.

[9] P. R. Joshi \& M. S. khan, (2017) "IOT Based Smart Power Management System Using WSN", International Research Journal of Engineering and Technology (IRJET), Vol. 04, No. 06, pp783-786.

[10] Boylestad, Robert L, (2007) “INTRODUCTORY CIRCUIT ANALYSIS". 